\title{
Naturalizing Peirce's Semiotics: Ecological Psychology's Solution to the Problem of Creative Abduction
}

\author{
Alex Kirlik and Peter Storkerson
}

\begin{abstract}
It is difficult not to notice a curious unrest in the philosophic atmosphere of the time, a loosening of old landmarks, a softening of oppositions, a mutual borrowing from one another on the part of systems anciently closed, and an interest in new suggestions, however vague, as if the one thing sure were the inadequacy of extant school-solutions. The dissatisfactions with these seems due for the most part to a feeling that they are too abstract and academic. Life is confused and superabundant, and what the younger generation appears to crave is more of the temperament of life in its philosophy, even though it were at some cost of logical rigor and formal purity.
\end{abstract}

William James (1904)

\begin{abstract}
The study of model-based reasoning (MBR) is one of the most interesting recent developments at the intersection of psychology and the philosophy of science. Although a broad and eclectic area of inquiry, one central axis by which MBR connects these disciplines is anchored at one end in theories of internal reasoning (in cognitive science), and at the other, in C.S. Peirce's semiotics (in philosophy). In this paper, we attempt to show that Peirce's semiotics actually has more natural affinity on the psychological side with ecological psychology, as originated by James J. Gibson and especially Egon Brunswik, than it does with non-interactionist approaches to cognitive science. In particular, we highlight the strong ties we believe to exist between the triarchic structure of semiotics as conceived by Peirce, and the similar triarchic stucture of Brunswik's lens model of organismic achievement in irreducibly uncertain ecologies. The lens model, considered as a theory of creative abduction, provides a concrete instantiation of at least one, albeit limited, interpretation of Peirce's semiotics, one that we believe could be quite fruitful in future theoretical and empirical investigations of MBR in both science and philosophy.
\end{abstract}

Alex Kirlik and Peter Storkerson

University of Illinois at Urbana-Champaign

e-mail: kirlik@illinois.edu

L. Magnani et al. (Eds.): Model-Based Reasoning in Science \& Technology, SCI 314, pp. $31-50$. springerlink.com

(c) Springer-Verlag Berlin Heidelberg 2010 


\section{Introduction}

As is often the case, psychologist-philosopher William James' observations of more than 100 years ago remain true today, especially so in the philosophy of science. And we do not think it surprising that it took the work of another psychologist-philosopher, Patrick Suppes [96, to provide perhaps the most convincing challenge of its era to the highly rigorous, formal, yet overly simplistic view that scientific theories expressed in a logical calculus are given meaning by the nature of their connections to empirical data in an unambiguous and logically direct way: "One of the besetting sins of philosophers of science is to overly simplify the structure of science" [96, p. 260]. The reasons we are not surprised to see an affinity between James and Suppes in this regard are twofold. First, and as noted by Suppes himself, "the branches of empirical science that have the least substantial theoretical developments often have the most sophisticated methods for evaluating evidence" 96, p. 260]. Second, the need for coherence in thought and action [78 continually nags at those of us who are practicing psychological or cognitive scientists to keep our speculations on the origins and nature of scientific knowledge grounded in our everyday experience of formulating hypotheses, designing experiments, and modeling and analyzing empirical data.

To admittedly oversimplify matters ourselves, the next significant developments in the philosophy of science that bear on the theme and thesis of this paper were made in the 1980s by authors such as van Frassen and Cartwright. In The Scientific Image (1980) van Frassen made tangible and influential strides toward advancing a "semantic", or intensively model-based view of theories and scientific activity. And in How the Laws of Physics Lie (1983), Cartwright provided a compelling argument that scientific laws cannot be read to be true of the world, but only of scientific models. These ideas are compelling to us as they are largely consistent with what we observe in both the practice and products of science, at least in our home disciplines.

Work by van Frassen, Cartwright and others has been persuasive in highlighting the centrality of model-based reasoning (MBR), both as a topic for psychological investigation and as a conceptual approach to the history and philosophy of science 65. In our preparations for, attendance at, and reflections upon, the conference on which this paper is based, we became aware of the fact that many researchers in this community, and especially those coming from a philosophical perspective, are now giving serious attention to the ideas of C.S. Peirce, and in particular his framework of semiotics and concept of abduction, as central to moving MBR research forward. This is true at both the disciplinary level, within psychology and philosophy individually, and especially at the multi-disciplinary level, to continue to forge ever stronger linkages between psychology and the philosophy of science with the goal to better understand the nature of creative abduction.

Our intent to contribute toward achieving this goal in this paper draws upon our backgrounds in (A.K.) basic and applied cognitive science (the 
latter often called "human factors engineering" or "human-computer interaction"), and (P.S.) theoretical and applied graphic design. As such, we are simultaneously engaged in understanding the principles underlying effective human learning and performance in interacting with the ecology, and also in creating ecologies to foster ever more effective and efficient interaction and communication.

Perhaps interestingly, we find that pursuing these activities, which might naively be described as theory and application, are not at all at odds, but are instead highly mutually reinforcing. Psychology is a woefully empirically under-constrained science, as its "data" are being continually manufactured in laboratories using one contrived task or another. As such, these data are largely artifactual rather than natural, and as such, provide a somewhat free floating empirical foundation, rather than one anchored in consensual agreements concerning direct observations of the physical world. In situations such as this, it would be perverse for psychological theorists to not warmly welcome the additional source of empirical constraint provided by application. If, for example, information display designs created by appeal to a particular psychological principle or theory result in predictably improved human learning and performance, it is more than likely that the principle or theory in question contains at least a grain of truth. As we create and then harvest these grains, we strive to contribute toward scientific goals and practical purposes at one and the same time.

\section{Peirce}

Peirce (1839-1914) was a mathematician, a chemist, and a philosopher of analytical bent. He was the founder of modern pragmatism: the view that things are what they do. In short a thing can only be known through its interactions with other things as those interactions disclose characteristics of that thing relative to the other things. Experience comes about through the interaction of an individual with the environment and others. Thus, all knowledge is ultimately based on such concrete experience. Objects, like a tree or a dollar as experienced are cognitive objects, created in the mind through cognitive processes of interpretation, that is, semiosis. Peirce described semiosis as a triadic relationship of representamen, cognitive object and intepretant or signification. The "representamen", also called a "sign vehicle", or "signal" is what comes into the eye or other sense organ. The cognitive object is what is perceived or apperceived. It is what the representamen is interpreted to be, for instance when a piece of paper is recognized as a dollar bill. The "interpretant", "significance" or "meaning" in the vernacular, is the content of the cognitive object, the notion of what being a dollar bill entails, that is, what money is, what can be bought with it, etc.

Peirce constructed a multi-faceted taxonomy of signs, starting with symbols, indexes and icons. Symbols are "arbitrary signs" in which the form of 
the sign is not related to its signification and the signification is assigned by convention. The dollar bill is a symbol. Its characteristics and markings are codes that have been assigned to connect the paper object as representamen to its cognitive object. Indexes are indicators. The angle of the sun and the shadows it projects can be used as clocks. A train can be used as a clock if one knows its schedule. These are natural signs. They reflect causal observations such as the movement of shadows. Icons function by having a similarity of resemblance or analogy. In a line chart, the line that rises as it goes to the right can be an iconic signification of "rising prices".

\section{Abduction, Iconicity, Diagrammatic Thinking, and Model Building}

Peirce was strongly anti-nominalist. In his view, knowledge is not based on concepts, but on interactions. For example, he discusses philosophers' accounts of the apprehension of self-evident truths as reflecting "the light of reason", nature or grace [79, pp. 12-13]. For Peirce, these accounts are theological rather than scientific. The history of science is equivocal, showing that "there is a natural light of reason, that is, that man's guesses at the course of nature are more often correct than could be otherwise accounted for, while the same facts actually prove that this light is extremely uncertain and deceptive, and consequently unfit to strengthen the principles of logic in any sensible degree" [79, p. 13].

How, then, does one get from observations to knowledge? Peirce's answer is in the chain of abduction, diagrammatic thinking, model building and empirical testing. The passage just quoted gives an account of abduction as a phenomenological sense of knowing or logically determining that something is or might be the case. Its track record is too good for abduction to be merely random guessing, yet it is probabilistic guessing nonetheless, and as we shall demonstrate in the remainder of this paper, it can be surprisingly adaptive or functional given that the conditions for learning through experience are met (e.g., the availability of timely and accurate feedback). Another aspect of abduction is the cognitive function of creating frameworks for interpreting and analyzing phenomena, which allows for the transition from solely intuitive to systematized knowledge: "An initial abduction makes a guess about how to formalize a given phenomenon, the deductive diagrammatic phase ... follows, and finally an inductive investigation concludes the picture, in which the diagrammatic result is compared to the actual empirical data" [94, p. 104].

Peirce's model of thinking is the diagram, which is a model of a phenomenon's structure/function; a diagram is "primarily an icon of relations" [81, p. 341]. It is an "operational account of similarity", 94, p. 90] which displays the structural relations of the object it diagrams in a way that enables one to see how the object functions. Looking at a diagram of a triangle, for example, involves using the physical diagram or figure drawn on paper as 
a sign that signifies first, the abstract triangle, with precisely straight lines of zero thickness and sharp vertices. From that cognitive object comes the next signification, of the abstract triangle as equivalent at any angle or scale, and finally, there is the abstract universal triangle as the combinations of lengths and angles that are possible in triangles [94, pp. 99-102]. These semiotic transformations of cognitive objects from the material figure on paper, to the abstract figure, to its potential permutations and structural interactions, mark the development of a mental model, which can be manipulated either mentally, or physically by drawing the diagram, folding and measuring, to reveal, in this case, the geometry of triangles. This is what prototyping in design and engineering does. Finally, Peirce states clearly that these diagrammatic models are not descriptions of things that exist in the universe, but models of what such things would be like were they to exist. Empirical research and experimental testing actually determines the relations of models to facts.

In short, Peirce's model is of the human being as a cognizing individual, in the world, whose knowledge has its origins in sensory experience (i.e., interaction with the world). One's knowledge is developed through a cognitive, semiotic system that is continually creating and computing models, building concepts and theories, and testing its models against reality. Peirce provides a philosophy of inquiry from which middle range theories and research methods can be developed, though he does not supply those theories and research tools.

\section{Saussure}

It would be convenient to end the discussion of semiotics here, but the general term has also been used to cover, conflate and confuse Peirce's semiotics with Fernand De Saussure's semiology. Semiology is also a theory of signs, but it is different from Peirce's semiotics. Semiology deals with symbols and language. It has a two-part theory of signification: the symbol or word and the meaning assigned to it. While Peirce explicitly bases his theory on the individual thinking human, Saussure's semiology is based on language as a collective set of meanings belonging to the culture, with individuals having little or no autonomy. By concentrating on language systems as primary constituents of cultural meanings, it enables language to be viewed as the primary source of meaning, rather than an expression of underlying cognitive function.

Semiology has its distinct uses and its notion of studying cultures through their languages has been enormously influential in the humanities, shaping twentieth century hermeneutics, anthropology, and cultural studies, enabling structuralism, post structuralism, deconstruction, and the "linguistic turn" in philosophy.

Further confusion has resulted from mixing semiotics and semiology. For example, Umberto Eco 23] described semiotics and semiology as a division of labor. In his "watergate" model, Eco described a system for regulating water 
flow in which a series of lights serve as arbitrary signs (symbols) indicating the flow and level of water according a code. He demonstrated that given such a code, it is possible to infer meanings, outside of those defined by the code. In this way, Eco wrapped the indexical sign, like the train that is used as a clock, around the coded arbitrary symbols. Eco used the same method in reverse order to describe recognizing a cat. Peirce's model is used in perceptual semiosis, seeing a shape as a cat, while the signification "cat" is a cultural/linguistic object, under the purview of semiology and the collective institution of language. This combining creates confusions and contradictions, as noted by Tomas Maldonado [67, pp. 119-123].

\section{Semiotics and Semiology}

Semiology was a key part of graphic design for much of the last century. It was quite useful as a tool in the design of the visual languages for specialized or multilingual contexts such as road signs and international gatherings. Peircian semiotics is used in technical communication and semiotic concepts are used in human factors to decompose and analyze interpretation in human judgment. Semiotics is also used in human-computer interaction, design of virtual environments and education [77. Semiotics has great potential as a framework to unify quickly developing but scattered literatures in naturalistic thinking as they are relevant to design. The semiotic model of diagrammatic thinking is of great importance, making possible a comprehensive understanding not only of diagrams, but the principles behind visual and spatial thinking, and abstraction in general (cf. Vorms, this volume [101]). It demonstrates the profound importance of graphical communication in the human leap from experiences in the world to the ability to think about those experiences in abstract terms: to make order of what is and to imagine what could be.

\section{Reception of Semiotic Theory in Graphical and Industrial Design}

For historical reasons, graphical and industrial design programs are most often located in art schools or departments, and are influenced by them. Academic fine arts cultures are often both humanist and decidedly anti-science. Here is one educator's reaction not only to semiotics, but to theory in general:

Semiotics is academic and abstract. I would venture that for many studio instructors, theory is simply beside the point. Better to discuss successful graphic design or the art canon with students and let them get to work. 14]

Professional graphic designers are often similarly inclined. Whatever influence semiotics and semiology have had in practice, they have often been viewed as problematical theories for many areas of design. Maldonado [67] criticized semiotics in a number of ways: 
The attempt to make use of a semiotic set of ideas to describe communicative (and even aesthetic) phenomena in the fields of architecture, urbanistics, and "industrial design" have not yielded the results that many expected, for may reasons, but above all for the lack of maturity in the semiotic itself. 67 p. 119]

This "lack of maturity" was reflected in semiotics-semiology confusion and the differing interpretations of Peirce by later theorists, but, particularly, the problem of operationally applying semiotics:

The semiotics [or the semiology] of architecture still remains at the metaphorical level. It would seem that, up to now, all efforts have been directed exclusively toward a substitution of the terminology of another, and little more.

67. p. 123]

That semiotics has not been widely used in design does not mean that it is not appropriate to the task of informing design. In fact, Peirce's semiotics is disciplined and well defined, and design fields based in science or engineering programs, rather than the arts, have been able to put semiotic thinking to good use. They have done so not much by consciously drawing on Peirce's works per se, but instead by drawing upon scientific theory that, to us, can be viewed as a quite legitimate and powerful naturalization of semiotics. We now turn our attention to this theory.

\section{Ecological Psychology: James J. Gibson and Egon Brunswik}

Although it is possible to trace selected aspects of ecological psychology to its functionalist origins in William James or John Dewey (see Heft [45]), ecological psychology emerged in mature form in the middle of the 20th century in the pioneering work of Egon Brunswik 9, 11] and James J. Gibson [33, 34, 35, on the problem of perception. These two theorists rejected idealist and Gestalt theorizing of the day, which stood upon an empirical foundation of perceptual biases, illusions, and errors, cataloged by laboratory scientists who thought they were investigating the fundamental aspects of perception by presenting simple stimuli to subjects using bite bars and tachistoscopes. Brunswik and Gibson agreed on the primary importance of a psychology focused on organism-environment relations (rather than solely the organism, human, or brain alone), a focus that defines what it means to take an ecological approach to psychology. These theorists also agreed that psychology should strive first and foremost to understand functional achievement, rather than to be satisfied merely by accumulating a body of findings on the frailties of perception in illusions, biases, or other errors. For more elaborate discussions of the relationships between Gibsonian and Brunswikian theory and method, see Kirlik [57, 52, Vicente [48], and Araujo, Davids and Passos [3].

Brunswik once followed a student around the Berkeley campus, cataloging her judgments of object sizes and distances, and found a much more accurate 
perceptual system than would have been expected considering the laboratory findings of the day. Gibson's early studies of military aviators alerted him to the existence of more perceptual richness and dynamism in optical stimulation than was then ever made available to laboratory subjects. His realist perceptual theory was based on the assumption that perception evolved to access this molar information, and thus what was then being observed in the laboratory was how perception had to contort itself to perform the "fundamental" task of accessing briefly displayed stimuli.

Brunswik and Gibson disagreed, however, on at least a few points. Most notably (and perhaps most fundamentally), they disagreed on whether the organism-environment relationship was fully deterministic and thus "lawful" (Gibson) or instead largely probabilistic (Brunswik). Brunswik once characterized his position on this matter with the statement "God may not gamble, animals and humans do" [10, p. 236]. In contrast, Gibson noted his discomfort with this position in his $(1957 / 2001)$ Contemporary Psychology review of Brunswik's (1956) book, the latter largely representing Brunswik's life's work. Characterizing Brunswik's position, Gibson [32] wrote:

Perception is based on insufficient evidence but, surprisingly, it is generally correct. By rights, the animal should not have functional contact with the environment, and yet it does. In his struggle with this dilemma, Brunswik never took refuge in subjectivism or in the sterile theory of the private phenomenal world. He was too well aware that functional behavior demands veridical perception. Nor would he accept the Gestalt theory of a brain process which would spontaneously produce the correct object in phenomenal experience. Instead he was driven to consider the difficult position of supposing that both the perceptual process and the environment itself are probabilistic, that is to say, imperfectly lawful. This is not a comfortable theory. Brunswik himself could not rest comfortably in the lap of uncertainty. Nevertheless he disciplined himself to make a virtue of what he considered a necessity. (p. 245)

Despite Gibson's discomfort with Brunswik's probabilism, he concluded his review by stating "His [Brunswik's] work is an object lesson in theoretical integrity" [32, p. 246].

\section{Brunswik's Probabilistic Functionalism}

Brunswik's ([9, 11]; also see Hammond \& Stewart [44]) ecological perspective on perception is reflected in his theory of "probabilistic functionalism". Brunswik's frame is pragmatic. The organism (a human or any other creature that acts in the world) seeks to act appropriately with the environment, in order to further its goals [97, p. 13]. This is the objective level at which the organism succeeds or fails-it stops at the cliff or falls off. To succeed and survive, it needs an internal model of its environment that functionally corresponds that environment in terms of the organism's ability to perceive and act. The organism's cognitive job is to use "proximal" sensory information 
it receives as indexes, signifying objects and events comprising the "distal" environment, to make that environment predictable. This is difficult in natural environments, because a distal cause in the environment can have any number of proximal sensory effects, and proximal effects (or stimuli) can have many distal causes.

The organism receives sensory information in different modes (sight, sound, touch) and from different organs (eyes, ears, skin). There is often redundancy between sensory inputs, and the organism integrates and weighs those various indicators in order to come up with a reliable picture or what is happening to what (seeing and hearing the hammer hit the nail). Put simply, by weighing many sensory signals, any of which can be in error, a very high degree of reliability is possible. People rely on their senses to perceive their environments, and their senses are generally highly reliable, and even more reliable when considered collectively rather than in isolation.

Brunswik' crystalized his approach in his "lens model" of perception, as shown in Figure 1. It models the functional correspondence between the environment and the organism's representation of the environment. The initial focal variable, which is the distal object, is available to the organism through a series of mediating sensory signals or signs, which Brunswik called "cues", along with spurious noise and errors. The organism's achievement of a "stable relationship" or functional correspondence of the terminal focal variable with respect to the environment, is effected through "vicarious functioning", in which the organism decides which signs or cues to pay attention to and what distal object, event, or property they signify. Most of the time, this happens spontaneously and below awareness. We human beings, for example, do not actually experience the proximal light on our retinas (the initial focal variable). We see the distal scene of objects around us (final focal variable), and we see them as the same objects ("stable relationship") under widely differing conditions of light, distance and angle. This is an achievement of perceptual interpretation, in which many different "cues" are weighed, so that we spontaneously see the clock on a distant church tower as bigger than the alarm clock on the night table next to us.

The lens model takes its name from the similarity between a graphical representation of the encounter between an organism and the environment and a convex lens [9, p. 20]. Note that the lens model was meant to describe both an organism's perceptual encounter with the environment as vicariously (opportunistically) mediated by a number of perceptual cues, as well as its overt, behavioral encounter with the environment as mediated by a number of actions, means-to-ends, or "habits". In the current context, however, we will mainly restrict the following discussion to solely perceptual encounters for simplicity.

Brunswik 9, 11] originally proposed measuring functional achievement (the top arc spanning, and connecting, the "terminal focus variable" or environmental criterion, and the observer's perceptual judgment) by linear association, or bivariate correlation. Achievement is therefore measured by 


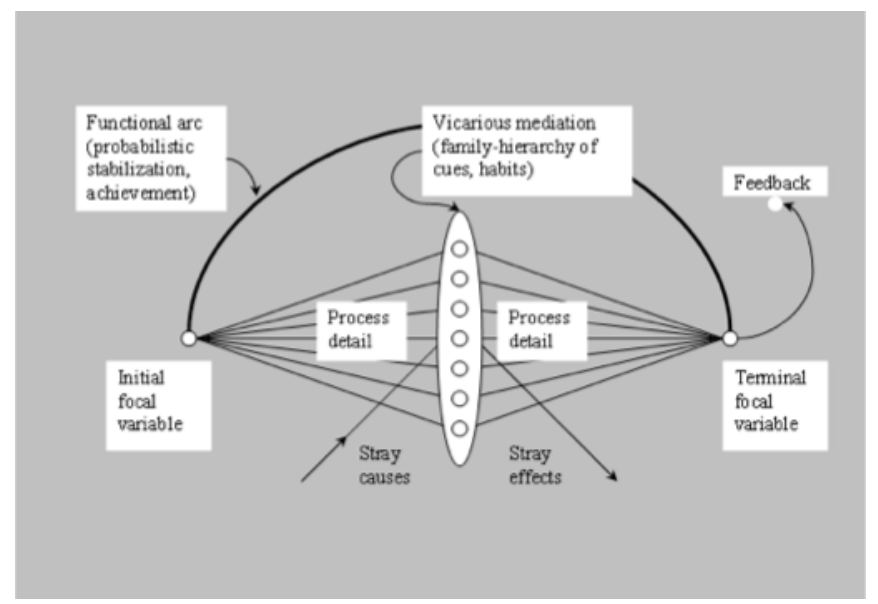

Fig. 1 The lens model (from Brunswik [9, p. 20]).

correlating the observer's judgments with the true values of the perceptual variable being judged. Hammond 43 , adopted this measure and first introduced the use of multiple linear regression to create a multiple correlation measurement of judgment as a function of fallible or probabilistic cues.

\section{The Lens Model Equation}

Figure 2 depicts a modern version of the lens model with associated quantitative variables and measures labeled. Achievement in perceptual judgment is indicated by the correlation coefficient $r_{Y O}$, where the subscripts represent the observer's judgment $(Y)$ of an environmental "Object" of judgment $(O)$. Perhaps the most important extension of Brunswik's original theory of probabilistic functioning was the development of the lens model equation [47, 99]. The lens model equation (LME) provides a mathematical representation of the lens model and partitions the overall correlation represented by the level of achievement $\left(r_{Y O}\right)$ into correlations related to the "ecological validities" or "trustworthiness" 9, 11 of the perceptual cues (that is, their statistical correlation the criterion - the "ev" values in Figure 21), the observer's cue utilizations (the "cu" values in Figure 2), the overall predictability of the environment, and the consistency with which an observer implements his or her perceptual judgment (cue-weighting) strategy.

At the basis of the LME are two parallel (typically linear regression) models, which represent the environmental and the observer sides of the lens model shown in Figure 2, The environmental model describes the overall correspondence between the cues $\left(X_{i}\right.$ 's) and the object of judgment $(O)$, and the observer model describes the overall correspondence between the cues $\left(X_{i}\right.$ 's) 


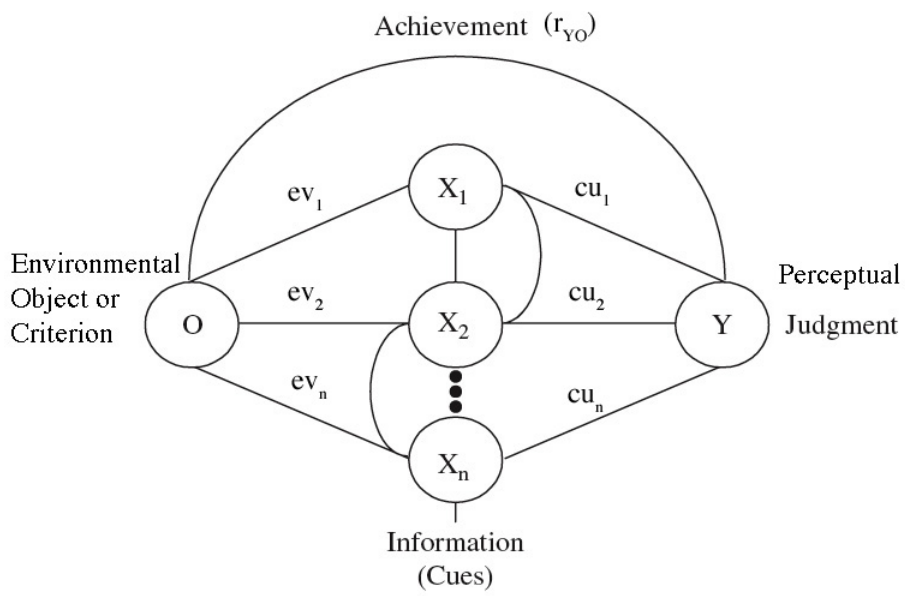

Fig. 2 The lens model with variables and measures identified (after Hammond 43]).

and the observer's judgments $(Y)$. Based on these two models, the resulting decomposition of achievement is depicted conceptually in Equation 1.

$$
\begin{array}{r}
\left(r_{Y O}\right)=\text { Environmental Predictability } \times \text { Consistency } \times \text { Knowledge }+ \\
+ \text { Unmodeled Knowledge }
\end{array}
$$

Environmental Predictability is the degree of correspondence between the perceptual cues and ecological criterion or object of perceptual judgment as reflected in the environmental model. Consistency is the degree of correspondence between the cues and observers' judgments as reflected in the observer model. Knowledge is the degree of correspondence between the outputs or predictions of the environmental and the observer models. This component is called Knowledge because it indicates the degree to which the observer correctly adjusts to the regularities of the ecology, or weights the cues adaptively (i.e., in accordance with their true ecological validities). Unmodeled Knowledge in Equation 1 is the degree of correspondence between the unpredictable portions of the environmental and observer models. Typically, but not always, this value is found to be marginal in human judgment 8 . For a meta-analysis of lens model applications in more than 250 tasks, see Karelaia \& Hogarth [50].

The decomposition shown in Equation 1 is accomplished with multiple linear regression. Thus, Environmental Predictability, Consistency, Knowledge, and Unmodeled Knowledge are measured using multiple correlation statistics. The mathematical form of the LME is shown in Equation 2, and its components are summarized below in Table 1.

$$
r_{Y O}=R_{O . X} G R_{Y . X}+C \sqrt{1-R_{Y . X^{2}}} \sqrt{1-R_{O . X^{2}}}
$$


Table 1 Components of the lens model equation.

\begin{tabular}{|l|l|l|}
\hline Component & Name & Description \\
\hline$r_{Y O}$ & Achievement & $\begin{array}{l}\text { Correlation between perceptual judgments } \\
\text { and the task criterion }\end{array}$ \\
\hline$R_{O . X}$ & $\begin{array}{l}\text { Criterion (Environ- } \\
\text { mental) Predictability }\end{array}$ & $\begin{array}{l}\text { Correlation between perceptually available } \\
\text { variables or cues and the ecological crite- } \\
\text { rion. }\end{array}$ \\
\hline$G$ & Knowledge & $\begin{array}{l}\text { Correlation between predictions of a } \\
\text { cue/variable-criterion model of the environ- } \\
\text { ment and the cue-response model of the ob- } \\
\text { server. }\end{array}$ \\
\hline$R_{Y . X}$ & $\begin{array}{l}\text { Perceptual or Cogni- } \\
\text { tive Control or Consis- } \\
\text { tency }\end{array}$ & $\begin{array}{l}\text { Correlation berceptual } \\
\text { cues/variables and perceptual judgments. }\end{array}$ \\
\hline$C$ & Unmodeled Knowledge & $\begin{array}{l}\text { Correlation between the residuals of envi- } \\
\text { ronmental and observer models: Adaptivity } \\
\text { to ecological structure that is not captured } \\
\text { in the scientists' models. }\end{array}$ \\
\hline
\end{tabular}

It is natural to identify lens model parameter $G$ (which measures the degree to which the observer's cue utilization pattern corresponds to the actual ecological validities of the cues) as a measure of the current level of "education of attention" that the observer has achieved [34. As discussed by Jacobs and Michaels 48, education of attention is Gibsonian terminology for a perceptual learning process in which observers "converge on more useful nonspecifying variables [cues] or even on variables that specify the to-be-perceived properties" [4, p. 131]. Because $G$ reflects the current degree of exactly this form of adaptivity, it is technically more precise to identify positive changes in $G$ as the education of attention, where any current, particular level of $G$ reflects the product of the learning or education process at any point in time.

Brunswik [9, 11 believed that if anything is likely to be fundamental and universal about human perception, it is exactly this context-specific, adaptive and highly opportunistic mode of cue search and utilization. Brunswik thought that this contextual and opportunistic aspect of perception (and indeed of all behavior, including habits and the achievement of distal goals by proximal means or actions - see 98, that is, vicarious functioning, was so fundamental that he constructed his entire theory of probabilistic functionalism and methodology of representative design around it (in addition to Brunswik's original work see Hammond \& Stewart [44).

As noted by Goldstein [42, Brunswik borrowed the term vicarious functioning from Hunter [46. Hunter noted that, whereas physiological functions normally carried out by one organ can rarely be carried out by another, a fundamental aspect of behavior studied by psychologists was that, when 
parts of the body typically used to carry out some type of behavior are unavailable, other parts of the body are often vicariously (opportunistically, adaptively) recruited to perform that behavior. Brunswik mainly used the term vicarious functioning to highlight the context-specific, highly opportunistic inter-substitutability of cues used on various occasions to support perception.

In essence, Brunswik's view was that if what was truly fundamental about perception was locally adaptive opportunism, rather than globally-adaptive laws, achievement in any particular ecological situation would have to be acquired through a feedback-guided, abductive process of trial and error learning. Much recent research conducted from a Brunswikian tradition (e.g., Gigerenzer \& Goldstein [37; Gigerenzer \& Selten [40; Gigerenzer, et al. 41]; Rothrock \& Kirlik [86]) finds that, when accurate feedback is available, people do learn to gravitate to using the most useful cues available to them in a particular ecology. As such, those working in a Brunswikian tradition recommend a shift away from a search for "global cognitive principles", and toward an "adaptive toolbox" 40] of largely "local solutions to local problems", (Gigerenzer \& Goldstein, 37]; Gigerenzer \& Kurz [38]).

Not surprisingly, then, research in this Brunswikian tradition takes a positive attitude toward passing epistemic judgment on these "local solutions" or "heuristics". In the Brunswikian tradition, a person using a locally adaptive (yet perhaps globally fallible) heuristic or solution is hardly viewed as being less than fully rational. Nor is that person viewed as demonstrating the limitations of cognitively constrained "bounded rationality" 89. Instead, such a person is viewed as using the most elegant and robust solution to the ecological challenge at hand (see Todd 64]).

That is, think of this set of ecologically local solutions to ecologically local problems (i.e., cognitive competence or even expertise, which is always restricted or local in some sense) as a product of evolution akin to the evolution of multiple species of plants and animals. Each has a niche, and none, including Homo sapiens, can simultaneously outperform all of those species more finely, albeit perhaps more narrowly, attuned to their particular niche or sub-ecology. Just as evolution has not been able to produce a context-free super-organism capable of eradicating all of the more ecologically narrowly located species, it has similarly been impossible for evolution to create a Laplacean super-mind 37. or super-observer as an engine for context-free, global rationality, as was once envisioned in the early, heady days of AIinspired cognitivism, and in what was once called the "received view" in the philosophy of science. An attractive alternative to such a super-mind (e.g., a fully general logical calculus of rationality) is a menagerie of narrower and locally restricted, yet reliable and robust, heuristic solutions to local problems, akin to an ecologically diverse and locally, rather than globally, adapted set of species. 


\section{Integration}

Gibson [34, 35] put forth a radical epistemology placing the lion's share of the burden for functional or adaptive behavior on the ecology and evolution. In his view, the world's lawful nature, and its almost limitless supply of information available in ambient energy arrays, combined with evolutionary time scales, equip organisms to seize on these resources to solve (or perhaps more appropriately, dissolve) the majority of their epistemic problems (e.g., Michaels and Carello [1]). In contrast, early, classical approaches to cognitive-representational cognitive science (e.g., Fodor [26]; Fodor \& Pylyshyn [27]) instead placed nearly the entire burden for functional or adaptive behavior on largely context-free, internal, cognitive computation and ratiocination, assuming a nearly totally disordered, and thus minimally informative ecology (cf. Cutting [16]).

We now know that neither of these extreme positions is tenable. A hearty dialogue and debate between, and among, those espousing views at opposing poles (nature vs. nurture, genes vs. environment, etc.) may be an efficient path forward in science. But we also know that largely dichotomous arguments such as these hardly ever result in truth being found at one pole or the other, but instead, and often inconveniently for those involved, lying stubbornly and (apparently) inelegantly in a theoretical middle ground.

Due to exactly this apparent inelegance, Brunswik's [9, 11] sophisticated, Darwinian theory of probabilistic functionalism did not receive a warm reception when it was proposed. In Brunswik's day, the debate between dichotomous empiricist and rationalist poles in psychology, though having a long tradition in philosophy, was only beginning to be informed by experimental evidence. Why accept an apparently inelegant middle ground when much more apparently elegant, fully empiricist and fully rationalist, positions were then still empirically viable?

Today, they are not, and the empirical research reviewed here indicates a convergence to a quite elegant, Darwinian solution able to accommodate aspects of both Gibson's 34, 35. theory of direct perception and Brunswik's [9, 11] theory of probabilistic functionalism. For empirical research demonstrating the utility of drawing simultaneously on both Brunswikian and Gibsonian theory see Kirlik [55, 53, 54, 56] and Davids, Button, Araujo, Renshaw \& Hristovski [17]. Recent Brunswikian research (e.g., Gigerenzer \& Engel [36]; Gigerenzer \& Goldstein [37]; Gigerenzer \& Selten [40; Gigerenzer et al. [41]) is extending this approach in creative directions.

Further evidence for a convergence in this direction can be found in alternative, yet possibly complementary research programs emerging with one foot planted firmly in ecological-evolutionary insights and themes (e.g. J. R. Anderson's rational analysis - see Anderson [1]) and the other planted firmly in the organism's cognitive contribution (e.g., J. R. Anderson's ACT-R - see Anderson, Bothell, Byrne, Douglass, Lebiere \& Quin [2]). Rational analysis and ACT-R can be viewed as complementary to Brunswik's and Gigerenzer's 
programs in many respects, albeit grounded in Bayesian rather than correlative statistics, and taking different phenomena as their core explananda (for additional discussion, see Kirlik [54, 57]). Each of these studies illustrates the successful use of a scientific theory in which the organism's cognitive contribution was assumed to consist largely in the reflection of, and adaptive response to the ecological regularities present in some particular (local) region of the human ecology.

\section{Application}

In psychology, Hammond \& Stewart 44 present a broad range of successful applications of probabilistic functionalism and the lens model in areas such as perceptual size constancy, interpersonal perception and interpersonal learning, social perception and moral judgment, medical judgment, vicarious functioning in teamwork, cognitive aging, emotional communication in musical performance, guidance counseling of adolescents, and evolutionary psychology. In human factors and human-computer interaction, Kirlik 54 presents a range of successful applications of probabilistic functionalism and the lens model in display design, fault diagnosis, searching for information on the Internet, collision avoidance in commercial aviation (both in air, and during surface taxi navigation), tactical judgment and decision making, the effects of time pressure on team performance, training, the design of decision aids, and achieving an effective coupling between people and cognitive automation.

\section{Conclusion: Peirce Revisited}

The large and rapidly growing body of work embracing and profitably using Brunswik's probabilistic functionalism, much of it design related, stands in sharp contrast to the way in which Peirce's semiotics has been (unprofitably) received in design disciplines based in the arts and humanities. We believe that this difference owes to the fact that Brunswik's triarchic, criterion-cuejudgment theory expressed in the lens model is tangible in a manner that Peirce's similar triarchic theory of semiotics is not. While semiotics is certainly more sweeping and encompassing than probabilistic functioning, this conceptual richness comes at a steep price.

We suggest that probabilistic functionalism, and more concretely, Brunswik's lens model, can legitimately be considered as a scientific naturalization of Peirce's semiotics. This theory and model captures how abductive knowledge is gained by an organism's ability to learn cue-criterion (Brunswik) or sign-referent (Peirce) relations over time, and in the presence of noise, through closed-loop interaction with the world that generates feedback revealing these relations. We would hope that this theory and model, viewed as a naturalization of semiotics, might similarly provide the philosophy of science with concrete resources to further its own inquiries into model-based reasoning and the nature of abduction. 


\section{Authors Note}

Portions of this paper have been drawn, in amended form, from Storkerson, P.: Antinomies of semiotics in graphic design. Visible Language 44, 6-39 (2010), Special Issue: Communication Design Failures, S. Poggenpohl, D. Winkler (eds.); and from Kirlik, A.: Brunswikian resources for event perception research. Perception 38, 376-398 (2009).

\section{References}

1. Anderson, J.R.: The Adaptive Character of Thought. Lawrence Erlbaum Associates, Hillsdale (1990)

2. Anderson, J.R., Bothell, D., Byrne, M.D., Douglass, S., Lebiere, C., Quin, Y.: An integrated theory of the mind. Psychological Review 111, 1036-1060 (2004)

3. Araujo, D., Davids, K., Passos, P.: Ecological validity, representative design, and correspondence between experimental task constraints and behavioral setting: Comments on Rogers, Kadar, and Costall. Ecological Psychology 19(1), 69-78 (2007)

4. Barthes, R.: Elements of Semiology. Hill and Wang, New York (1964)

5. Bonsiepe, G.: Visual/verbal rhetoric. UlM 14/15/16, 23-40 (1965)

6. Bonsiepe, G.: A method for quantifying order in typographic design. The Journal of Typographic Research 2(3), 203-220 (1968)

7. Bonsiepe, G.: The uneasy relationship between design and design research. In: Mitchel, R. (ed.) Design Research Now, pp. 25-39. Springer, Berlin (2008)

8. Brehmer, B.: The psychology of linear judgment models. Acta Psychologica 87, 137-154 (1994)

9. Brunswik, E.: The Conceptual Framework of Psychology. University of Chicago Press, Chicago (1952)

10. Brunswik, E.: Representative design and probabilistic theory in a functional psychology. Psychological Review 62, 193-217 (1955)

11. Brunswik, E.: Perception and the Representative Design of Psychological Experiments. University of California Press, Berkeley (1956)

12. Candlin, F.: Practice-based doctorates and questions of academic legitimacy. International Journal of Art and Design Education 19(1), 96-101 (2000)

13. Cartwright, N.: How the Laws of Physics Lie. Oxford University Press, New York (1983)

14. Crisp, D.: Book review of visible signs: An introduction to semiotics and the fundamentals of creative design. Print 58(2), 34 (2004)

15. Crotty, M.: The Foundations of Social Research: Meaning and Perspective in the Research Process. Sage Publications, London (1998)

16. Cutting, J.E.: Two ecological perspectives: Gibson vs. Shaw and Turvey. The American Journal of Psychology 95(2), 199-222 (1982)

17. Davids, K., Button, C., Araujo, D., Renshaw, I., Hristovski, R.: Movement models from sports provide representative task constraints for studying adaptive behavior in human movement systems. Adaptive Behavior 14(1), 73-95 (2006)

18. Deely, J.: Basics of Semiotics. University of Indiana Press, Bloomington (1990) 
19. Basel School of Design Visual Communication Institute: Welcome (2009), http://www.baselschoolofdesign.ch (Retrieved, June 23, 2009)

20. Domandi, M., Mead, M.: Anthropology and glyphs. Print 23(6), 50-53 (1969)

21. Dreyfus, H.: Symbol Sourcebook. Van Nostrand Reinhold, New York (1984)

22. Dreyfus, P.: Design education today: Turmoil and transition. Print 23(5) (1969)

23. Eco, U.: A Theory of Semiotics. Indiana University Press, Bloomington (1979)

24. Ehses, H.: Representing Macbeth: A case study in visual rhetoric. Design Issues 1(1), 53-63 (1984)

25. Flyvberg, B.: Making Social Science Matter: Why Social Inquiry Fails and how it Can Succeed Again. Cambridge University Press, Cambridge (2001)

26. Fodor, J.A.: Methodological solipsism considered as a research strategy in cognitive psychology. Behavioral and Brain Sciences 3, 63-110 (1980)

27. Fodor, J.A., Pylyshyn, Z.W.: How direct is visual perception? some reflections on Gibson's ecological approach. Cognition 9, 139-196 (1981)

28. Frascara, J.: User-Centered Graphic Design: Mass Communications and Social Change. Taylor and Francis, London (1997)

29. Frassen van, B.: The Scientific Image. Oxford University Press, New York (1980)

30. Frutiger, A.: Signs and Symbols: Their Design and Meaning. Studio Editions, Zurich (1978/1989)

31. Frutiger, A.: Type Sign Symbol. Editions ABC, Zurich (1980)

32. Gibson, J.: Survival in a world of probable objects. In: Hammond, K.R., Stewart, T. (eds.) The Essential Brunswik, pp. 244-246. Oxford University Press, Oxford (2001) (Reprinted)

33. Gibson, J.J.: The Perception of the Visual World. Houghton Mifflin, Boston (1950)

34. Gibson, J.J.: The Senses Considered as Perceptual Systems. Houghton Mifflin, Boston (1966)

35. Gibson, J.J.: The Ecological Approach to Visual Perception. Lawrence Erlbaum, Hillsdale (1986), Originally work published in 1979

36. Gigerenzer, G., Engel, C.: Heuristics and the Law. MIT Press, Cambridge (2006)

37. Gigerenzer, G., Goldstein, D.G.: Reasoning the fast and frugal way: Models of bounded rationality. Psychological Review 103, 650-669 (1996)

38. Gigerenzer, G., Kurz, E.M.: Vicarious functioning reconsidered: A fast and frugal lens model. In: Hammond, K.R., Stewart, T.R. (eds.) The Essential Brunswik, pp. 342-347. Oxford University Press, New York (2001)

39. Gigerenzer, G., Murray, D.: Cognition as Intuitive Statistics. Lawrence Erlbaum, Hillsdale (1987)

40. Gigerenzer, G., Selten, R.: Bounded Rationality: The Adaptive Toolbox. MIT Press, Cambridge (2001)

41. Gigerenzer, G., Todd, P.M.: The ABC Research Group: Simple Heuristics that Make Us Smart. Oxford University Press, New York (1986)

42. Goldstein, W.M.: Introduction to Brunswikian theory and method. In: Kirlik, A. (ed.) Adaptive Perspectives on Human-Technology Interaction, pp. 10-24. Oxford University Press, New York (2006)

43. Hammond, K.: Probabilistic functionalism and the clinical method. Psychological Review 62, 255-262 (1955) 
44. Hammond, K., Stewart, T.R.: The Essential Brunswik. Oxford University Press, Oxford (2001)

45. Heft, H.: Ecological Psychology in Context: James Gibson, Roger Barker, and the Legacy of William James Radical Empiricism. Lawrence Erlbaum, Mahwah (2001)

46. Hunter, W.S.: The psychological study of behavior. Psychological Review 39, 1-24 (1932)

47. Hursch, C.J., Hammond, K.R., Hursch, J.L.: Some methodological considerations in multiple-cue probability studies. Psychological Bulletin 71, 42-60 (1964)

48. Jacobs, D.M., Michaels, C.F.: On the apparent paradox of learning and realism. Ecological Psychology 14, 127-139 (2002)

49. James, W.: A world of pure experience. Journal of Philosophy, Psychology, and Scientific Methods 1(20, 21) (1904)

50. Karelaia, N., Hogarth, R.M.: Determinants of linear judgment: A metaanalysis of lens studies. Psychological Bulletin 134(3), 404-426 (2008)

51. Kinross, R.: Semiotics and designing. Information Design Journal 4(3), 190$198(1986)$

52. Kirlik, A.: On Gibson's review of Brunswik. In: Hammond, K.R., Stewart, T.R. (eds.) The Essential Brunswik, pp. 238-242. Oxford University Press, New York (2001)

53. Kirlik, A.: Reiventing intelligence for an invented world. In: Sternberg, R.J., Preiss, D.D. (eds.) Intelligence and technology: The impact of tools on the nature and development of human abilities, pp. 105-134. Lawrence Erlbaum Associates, Mawhah (2005)

54. Kirlik, A.: Adaptive Perspectives on Human-Technology Interaction: Methods and models for cognitive engineering and human-computer interaction. Oxford University Press, New York (2006)

55. Kirlik, A.: Requirements for psychological models to support design: Toward ecological task analysis. In: Flach, J., Hancock, P., Caird, J., Vicente, K. (eds.) Global Perspectives on the Ecology of Human-Machine Systems, pp. 68-120. Lawrence Erlbaum Associates, Mahwah (2006)

56. Kirlik, A.: Ecological resources for modeling embedded cognition and interactive behavior. In: Gray, W. (ed.) Integrated Models of Cognitive Systems, pp. 194-210. Oxford University Press, New York (2007)

57. Kirlik, A.: Brunswikian resources for event perception research. Perception 38(3), 376-398 (2009)

58. Koffka, K.: Principles of Gestalt Psychology. Brace and World, Harcourt (1935)

59. Krampen, M.: Symbols in graphic communication. Design Quarterly 62, 1-31 (1965)

60. Kripopendorff, K.: The Semantic Turn: A New Foundation for Design. Taylor and Francis, London (2006)

61. Lakoff, G., Johnson, M.: Philosophy in the Flesh. Basic Books, New York (1999)

62. Lausen, M.: Design for Democracy: Ballot and Election Design. University of Chicago Press, Chicago (2007)

63. Lausen, M.: Designing change. Design matters. Univeristy of Illinois, Urbana Champaign (2009), http://designmatters.art.uiuc.edu/Videos/marcia-lausen-2/

(Retrieved, June 24, 2009) 
64. Todd, P.M.: Fast and frugal heuristics for environmentally bounded minds. In: Gigerenzer, G., Selten, G. (eds.) Bounded Rationality: The Adaptive Toolbox, pp. 51-70. MIT Press, Cambridge (2002)

65. Magnani, L., Nersessian, N.J., Thagard, P. (eds.): Model-Based Reasoning in Scientific Discovery. Kluwer Academic/Plenum Publishers, New York (1980)

66. Maier, M.: Basic Design Principles: The Foundation Program at the School of Design. Van Nostrand Reinhold Publishers, Basel (1977)

67. Maldonado, T.: Nature, Design and Revolution: Toward a Critical Ecology. Harper \& Row, New York (1972)

68. Maldonado, T., Bonsiepe, G.: Science and design. ULM 10/11, 10-16 (1965)

69. Manning, A., Amare, N.: Visual-rhetoric ethics: Beyond accuracy and injury. Technical Communications 53(2), 195-211 (2006)

70. Marcus, A.: m-locos ui: A universal visible language for global mobile communication. In: Jacko, J.A. (ed.) HCI 2007. LNCS, vol. 4552, pp. 144-153. Springer, Heidelberg (2007)

71. Michaels, C.F., Carello, C.: Direct Perception. Prentice-Hall, Englewood Cliffs (1981)

72. Moles, A.: The legibility of the world: A project of graphic design. Design Issues 3(1), 43-53 (1986)

73. Morris, C.: Foundations of the Theory of Signs. University of Chicago Press, Chicago (1938)

74. Neurath, M.: Isotype. Instructional Science 3(2), 127-150 (1974)

75. Neurath, O.: BASIC by Isotype. Kegan Paul, Trench, Trubner \& Co., New York (1937)

76. Ockerse, T., van Dijk, H.: Semiotics and graphic design education. Visible Language 13(4), 358-378 (1979)

77. de Oliveira, O., Baranauskas, M.: Semiotics as a basis for educational software design. British Journal of Educational Technology 31(2), 153-161 (2000)

78. Thagard, P.: Coherence in Thought and Action. MIT Press, Cambridge (2002)

79. Peirce, C.: Logic. In: Hartshorne, C., Weiss, P. (eds.) The Collected Papers of Charles Sanders Peirce, vol. I-II. Harvard University Press, Cambridge (1933)

80. Peirce, C.: Pragmatism and pragmaticism. In: Hartshorne, C., Weiss, P. (eds.) The Collected Papers of Charles Sanders Peirce, vol. V. Harvard University Press, Cambridge (1933)

81. Peirce, C.: The simplest mathematics. In: Hartshorne, C., Weiss, P. (eds.) The Collected Papers of Charles Sanders Peirce, vol. V. Harvard University Press, Cambridge (1933)

82. Polanyi, M.: The Tacit Dimension. Routledge \& Kegan Paul, London (1966)

83. Ramachandran, S.: Purple numbers and sharp cheese (2003), http://www.bbc.co.uk/radio4/reith2003/lecture4.shtml BBC Reith Lectures 2003: The Emerging Mind. BBC Radio 4. (Retrieved June 1, 2009)

84. Ramachandran, V., Hubbard, E.: Synesthesia: What does it tell us about the emergence of qualia, metaphor, abstract thought, and language? In: van Hemmen, J., Sejnowski, T. (eds.) 23 Problems in Systems Neuroscience, pp. 432-473. Oxford University Press, Oxford (2006)

85. Ramachandran, V., Hubbard, E., Butcher, P.: Synesthesia, cross-activation and the foundations of neuroepistemology. In: Robertson, L., Sagiv, N. (eds.) Synesthesia: Perspectives from cognitive neuroscience, pp. 147-190. Oxford University Press, Oxford (2004) 
86. Rothrock, L., Kirlik, A.: Inferring rule-based strategies in dynamic judgment tasks. IEEE Transactions on Systems, Man, and Cybernetics: Part A: Systems and Humans 33(1), 58-72 (2003)

87. Rust, C.: Unstated contributions - how artistic inquiry can inform interdisciplinary research. International Journal of Design 1(3), 69-76 (2008)

88. Saussure, F.: Course in General Linguistics. In: Baskin (Tr), E., Bally, C., Reidlinger, A. (eds.) Philosophical Library (1966)

89. Simon, H.: Models of Man. Wiley and Sons, New York (1957)

90. Skaggs, S.: Introduction. Zed 4, 8-9 (1997)

91. Skaggs, S., Shank, G.: Codification, inference and specificity in visual communication design. Zed 4, 54-59 (1997)

92. Sless, D.: Design philosophy. communication research institute of australia (2009), http://www.communication.org.au/dsblog/?p=43 (Retrieved June 23, 2009)

93. STC: Stc ethical principles for commmunicators (1998), http://www.stc.org/about/policy_ethicalPrinciples.asp

Society for Technical Communication (Retrieved July 5, 2009)

94. Stjernfeldt, F.: Diagrammatology: An Investigation on the Borderlines of Phenomenology, Ontology, and Semiotics. Springer, Berlin (2007)

95. Storkerson, P.: Is disciplinary research possible in communication design? Design Research Quarterly 3(2), 1-8 (2008), http://www.drsq.org (Retrieved, July 15, 2009)

96. Suppes, P.: Models of data. In: Nagel, E., Suppes, P., Tarski, A. (eds.) Logic, Methodology, and Philosophy of Science: Proceedings of the 1960 International Congress, pp. 252-161 (1960)

97. Tolman, E.: Purposive Behavior in Man and Animals. University of California Press, Berkeley (1951)

98. Tolman, E.C., Brunswik, E.: The organism and the causal texture of the environment. Psychological Review 43, 43-77 (1935)

99. Tucker, L.R.: A suggested alternative formulation in the developments of Hursch, Hammond, and Hursch, and Hursch, Hammond \& Todd. Psychological Review 71(6), 528-530 (1964)

100. Vicente, K.J.: Beyond the lens model and direct perception: Toward a broader ecological psychology. Ecological Psychology 15, 241-267 (2003)

101. Vorms, M.: The theoretician's gambits: Scientific representations, their formats and content. In: SCI, vol. 314. Springer, Heidelberg (2010)

102. Wertheimer, M.: Principles of perceptual organization. In: Wertheimer, M., Beardslee, M. (eds.) Readings in Perception, pp. 115-135. Van Nostrand, Princeton (1958)

103. Winkler, D.: Design practice and education: Moving beyond the Bauhaus model. In: Frascara, J. (ed.) User-centered Graphic Design: Mass Communications and Social Change, pp. 129-135. Taylor \& Francis, London (1997)

104. Winn, W., Hoffman, H., Osberg, K.: Semiotics, cognitive theory and the design of objects, actions and interactions in virtual environments. Journal of Structure, Learning and Intelligent Systems 14(1), 29-49 (1999) 